\title{
USO DO INSTRUMENTO PRISMA E DE ANÁLISE DE DADOS COMO SUPORTE AO LEVANTAMENTO E CATEGORIZAÇÃO DE KPIS DE SSO
}

\section{USE OF THE PRISMA INSTRUMENT AND DATA ANALYSIS TO SUPPORT THE SURVEY AND CATEGORIZATION OF OH\&S KPIS}

Recebido em: 30 ago. 2020

Aprovado em: 26 abr. 2021

Versão do autor aceita publicada online: 26 abr. 2021

Publicado online: 30 jun. 2021

Como citar esse artigo - American Psychological Association (APA):

Costa, F. V., \& Lima, G. B. A. (2023, jan./mar.). Uso do instrumento PRISMA e de análise de dados como suporte ao levantamento e categorização de KPIs de SSO. Exacta, 21(1), 101-129. https://doi.org/10.5585/exactaep.2021.18027

Submeta seu artigo para este periódico $\}$

Processo de Avaliação: Double Blind Review

Editor: Dr. Luiz Fernando Rodrigues Pinto

Dados Crossmark 



\author{
USE OF THE PRISMA INSTRUMENT AND DATA ANALYSIS TO SUPPORT THE SURVEY AND \\ CATEGORIZATION OF OH\&S KPIS
}

(iD) Felipe Vaz Costa ${ }^{1}$
(iD) Gilson Brito Alves Lima

Resumo: Este artigo tem como objetivo levantar um conjunto de indicadores de Saúde e Segurança Ocupacional (SSO) para auxiliar no processo de tomada de decisões na área. A metodologia utilizada foi composta pela realização de uma revisão sistemática da literatura, de forma a listar os IndicadoresChave de Desempenho (Key Performance Indicator - KPI) mais frequentemente citados e categorizá-los em proativos e reativos. Em seguida, se realizou uma pesquisa de campo com profissionais da área quando, através de um questionário, estes especialistas classificaram a relevância dos indicadores listados pela literatura, conforme sua percepção. Os resultados obtidos nesta revisão concluíram a existência de 120 indicadores de desempenho. Após análise da frequência de citações destes KPIs pela literatura, sua união com demais indicadores considerados mandatórios e a percepção dos profissionais da área de SSO quanto a relevância dos mesmos, identificou-se um conjunto de 24 KPIs habilitados a comporem o conjunto proposto.

Palavras-chave: saúde e segurança ocupacional. indicadores de desempenho. tomada de decisões.

Abstract: This article aims to raise a set of Occupational Health and Safety KPIs to assist in the decisionmaking process in the area. The methodology used was composed of a systematic literature review, in order to list the performance indicators most frequently cited in the literature and classify them as proactive and reactive. Then, a field research was carried out with professionals in the field when, through a questionnaire, these specialists classified the relevance of the KPIs listed by the literature, according to their perception, through a Likert scale. The results obtained in the literature review concluded the existence of 120 performance indicators. After analyzing the frequency of citations of these KPIs by the literature, their union with other indicators considered mandatory and the perception of $\mathrm{OH} \& S$ professionals regarding their relevance, a set of $24 \mathrm{KPIs}$ qualified to compose the proposed set was identified.

Keywords. occupational health and safety. performance indicators. decision-making.

\footnotetext{
${ }^{1}$ Universidade Federal Fluminense / Felipe Vaz Costa nasceu em Niterói, Brasil. Engenheiro Eletricista/Telecomunicações. Possui Especialização em Engenharia de Segurança do Trabalho. Possui experiência profissional como Engenheiro de Segurança do Trabalho. Seu foco de pesquisa acadêmica tem ênfase nas áreas de Gerênciamento de Riscos e Saúde e Segurança Ocupacional

${ }^{2}$ Universidade Federal Fluminense / Gilson Brito Alves Lima nasceu em Niterói, Brasil. Engenheiro Civil. Tem Especialização em Engenharia de Segurança do Trabalho e fez mestrado em Engenharia Civil na UFF e Doutorado em Engenharia de Produção na COPPE/UFRJ. Professor Titular da Universidade Federal Fluminense. Credenciado nos Cursos de Mestrado e Doutorado em Sistemas de Gestão da UFF. Tem experiência profissional em Consultoria Técnica na Indústria de Energia. Seu foco de pesquisa acadêmica tem ênfase nas áreas de Gerência de Riscos, Manutenção, Segurança, Meio Ambiente e Sustentabilidade Organizacional
} 
Introdução

Com o crescimento da competitividade entre as empresas, as organizações tendem a buscar resultados cada vez melhores com cada vez menos recursos (Sanders \& Loos, 2019).

Desta forma, no atual cenário em que as decisões de alocação de recursos e de definição de prioridades exigem bases de evidências cada vez mais sólidas, é essencial que os benefícios trazidos pela promoção de SSO ejam convincentemente demonstrados através de estudos empíricos (Luyten, Steel, \& Godderis, 2017).

Tal visão é compartilhada por Guarda, León, Augusto, Pinto, Barrionuevo, \& Villao (2018), quando os autores ressaltam a importância da correta tomada de decisões para as organizações de forma a aumentar seus lucros, gerir seus riscos e garantir o bom desempenho geral das empresas.

Neste sentido, o estabelecimento de indicadores de desempenho apresentam-se como valiosos procedimentos gerenciais para o auxílio a tomada de decisões, conforme corroboram Nagyova, \& Pacaiova (2009). Segundo os autores, os KPIs são aspectos quantificáveis (métricos) que refletem os principais fatores a serem gerenciados pelas empresas para alcançarem seus objetivos.

Neste sentido, a pesquisa se justifica devido à escassa produção de conteúdo que aborde um conjunto de indicadores listado pela literatura especializada e ratificado por profissionais da área de SSO através de um survey, contribuindo assim para o preenchimento desta lacuna.

Diante do exposto, o objetivo deste artigo é mapear indicadores de desempenho de Saúde e Segurança Ocupacional capazes de auxiliar os gestores de SSO em sua tomada de decisão.

Para o cumprimento deste objetivo buscou-se responder às seguintes questões de pesquisa:

- De acordo com a literatura, quais indicadores, relacionados à Saúde e Segurança Ocupacional, são utilizados para tomada de decisão de SSO?

- De acordo com os profissionais de SSO, quais indicadores, listados pela literatura, são relevantes para a tomada de decisão em SSO?

De forma complementar, estes indicadores serão categorizados entre proativos e reativos, quando se buscará identificar a existência de uma maior relevância de um tipo sobre o outro, também segundo a percepção dos profissionais citados.

Neste contexto, o artigo está elaborado em 5 seções. A seção 1 é composta pela introdução ao tema, através da contextualização da importância da utilização dos indicadores adequados para as tomadas de decisões em SSO. Na seção 2 encontra-se o referencial teórico que embasou o estudo. A seção 3 apresenta a metodologia utilizada para a realização da pesquisa. A sessão 4 traz as discussões 
sobre os dados encontrados na revisão sistemática da literatura, e na Sessão 5 são apresentadas as considerações finais, compostas pela conclusão da pesquisa desenvolvida.

\section{Referencial Teórico}

Indicadores Chave de Desempenho (KPI) em Saúde e Segurança Ocupacional

Para que se tenha uma visão de como os indicadores foram evoluindo ao longo do tempo, os autores Yang, Macnab, Yang, \& Fan (2015) fazem uma evolução histórica de como o foco dos indicadores foram mudando ao longo do tempo e apontam como a Fase I, o período compreendido entre 1880 a 1980, quando os principais indicadores eram os financeiros e o objetivo das organizações era o lucro, o retorno sobre os investimentos e a produtividade, dentre outros. A Fase II abrangeria o final de 1980 em diante, quando a competição global se tornou estratégica e o foco das organizações se volta para o equilíbrio entre medidas de curto e longo prazo, adoção e valorização dos ativos tangíveis e intangíveis.

É nesse sentido que Salles \& lozzi (2010) argumentam que a avaliação de desempenho empresarial baseada apenas em indicadores contábeis e financeiros tem se mostrado insuficiente para as organizações.

É neste contexto que, como apontam Galindo \& Monge (2018), os Indicadores Chave de Desempenho passam a ser amplamente usados como uma ferramenta para medir o desempenho de uma organização e, consequentemente, possibilitar o seu gerenciamento.

Desta forma, selecionar os KPIs ou as métricas principais se constitui em um desafio, segundo Mansoori, Novak, Sivit, \& Ros (2013), porque esses devem refletir as metas organizacionais de forma objetiva e serem naturalmente mensuráveis, acessíveis e claramente compreensíveis.

Nesse sentido, Miler, Gabaj, Dukic, \& Simundic (2018) citam que os KPIs devem ser específicos, mensuráveis, realizáveis, relevantes e oportunos (SMART - Specific, Measurable, Attainable, Relevant and Time based).

No que tange à Saúde e Segurança Ocupacional, Robson, Ibrahim, Hogg-Johnson, Steenstra, van Eerd, \& Amick III, (2017), citam que os profissionais da área fazem distinção entre dois tipos de medidas de desempenho: indicadores reativos e proativos. Os indicadores reativos (também conhecidos como indicadores atrasados ou negativos) medem resultados de SSO, tais quais, taxas de lesões e doenças. Os indicadores proativos (também conhecidos como indicadores principais ou positivos) medem as atividades, condições e eventos do local de trabalho que são relevantes ou podem determinar resultados de SSO, tais quais medidas do clima de segurança, frequência das inspeções no local de trabalho e níveis de exposição ao ruído. 
Em contraste com os indicadores reativos (lagging indicators), que se concentram nos resultados retrospectivos, um indicador principal (leading indicator) é associado a atividades proativas e consiste em elementos selecionados do Sistema de Gestão da Segurança e Saúde do Trabalho (SGSST)).

Neste contexto, Almost et al. (2018) ressaltam que houve um movimento de afastamento dos indicadores reativos, em direção a avaliações "líderes", proativas ou preditivas.

Trethewy (2003), argumenta que agregar diferentes tipos de Indicadores Positivos de Desempenho ou leading indicators, permitem uma avalição precisa do desempenho de segurança de uma organização.

Neste sentido, algumas pesquisas vêm sendo realizadas com o objetivo de identificar indicadores de desempenho em SSO, como é o caso do trabalho realizado por Podgórski (2015), que realizar uma revisão da literatura sobre os principais indicadores de desempenho de segurança trazendo um conjunto de $34 \mathrm{KPIs}$ proativos para a tomada de decisão na área.

De forma similar, Korkusuz et al. (2018), realizaram uma pesquisa a fim de investigar os principais KPIs necessários para medir o desempenho em saúde e segurança ocupacional, quando apresentam 15 indicadores chave de desempenho relevantes para a área.

\section{Método de Pesquisa}

\section{Revisão sistemática da literatura}

A revisão sistemática da literatura, utilizada para o mapeamento dos indicadores de SSO listados pela literatura especializada, foi realizada a partir da adaptação da recomendação PRISMA - (Principais Itens para Relatar Revisões Sistemáticas e Meta-análises), que consiste em um checklist de 27 itens e cujo objetivo é ajudar os autores a melhor elaborarem o relato das revisões sistemáticas e meta-análises de suas pesquisas (Moher, Shamseer, Clarke, Ghersi, Liberati, Petticrew, ... \& Stewart, 2015).

Para a aplicação do checklist e do fluxograma PRISMA fez-se necessária uma adaptação da sistemática devido as características do presente estudo.

O fluxograma descrito pela figura 1 sintetiza as quatro fases descritas na recomendação PRISMA. 
Figura 1

Fluxograma PRISMA

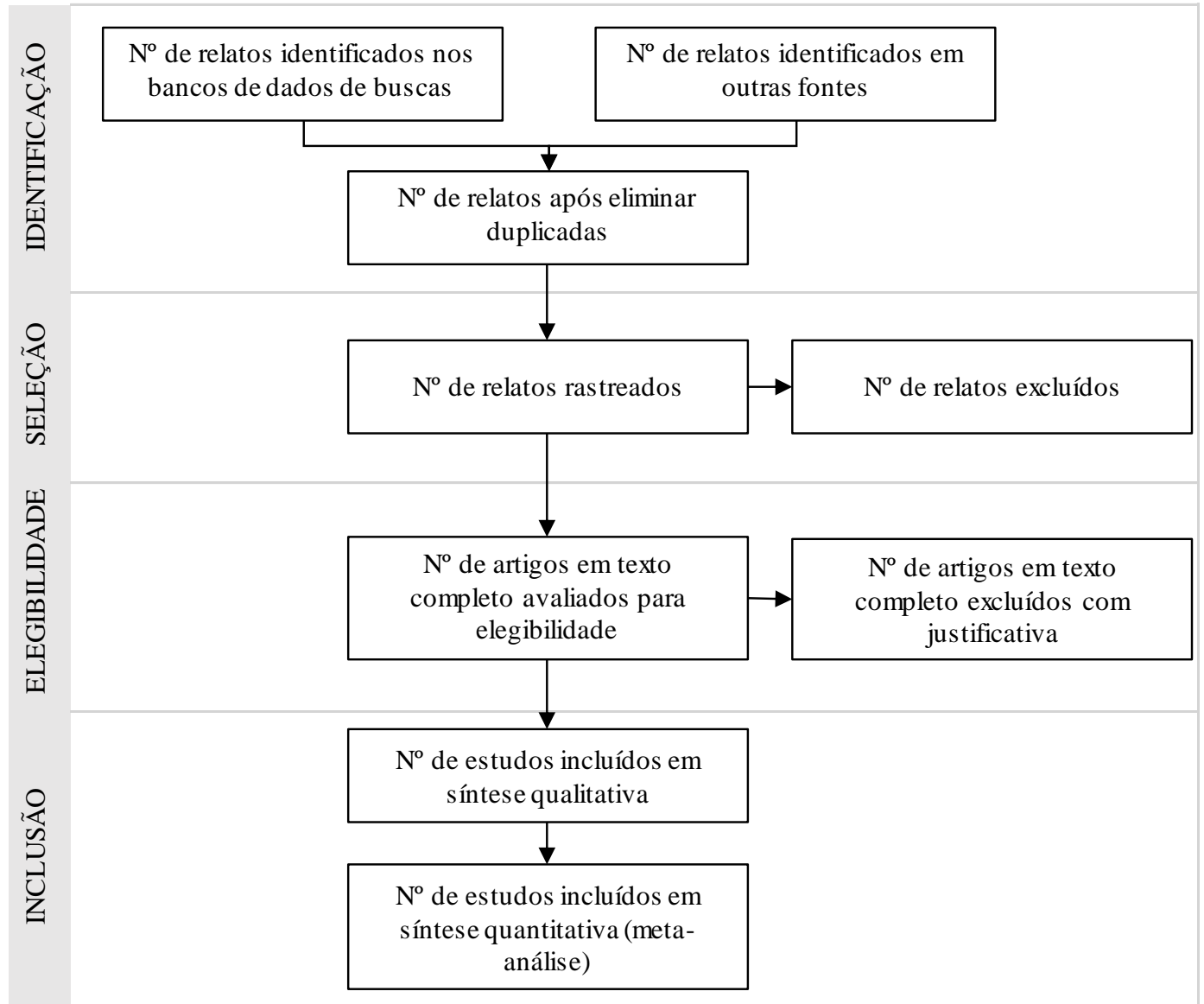

Fonte: MOHER et al. (2015)

A partir da lógica proposta pela recomendação PRISMA foram selecionados quatro critérios: identificação, seleção, elegibilidade e inclusão, conforme descrição abaixo:

a) Identificação

Para o cumprimento do critério de identificação dos trabalhos que pudessem auxiliar na elaboração desse estudo, em setembro de 2019 foi realizada uma revisão sistemática, através de pesquisa bibliográfica nas bases de dados tradicionais Scopus e Web of Science. Tal pesquisa seguiu os seguintes critérios:

- Lógica da String de pesquisa: (Indicator OR KPI) AND ("occupational health and safety" OR "Health safety and enviroment" OR "Safety, Health and Environment" OR "Quality, Safety, 
Environment and Health" OR "quality, safety, occupational health and environmental" $O R$ "OHS" OR "OSH" OR "HSE" OR "QSEH" OR "QSHE" OR "QHSE" OR "SHE");

- Período de publicação: Não houve limitação. Todo o período disponível nas bases foi considerado;

- Idioma: Inglês e Português

b) $\underline{\text { Seleção }}$

A fase de seleção consistiu na leitura dos títulos e resumos dos relatos obtidos nas bases de dados. Essa primeira triagem focou na abordagem de relatos que abordassem a questão dos indicadores em SSO.

c) Elegibilidade

A fase de elegibilidade contemplou a leitura completa dos artigos e, nesse estágio, foram considerados apenas aqueles que tivessem como foco o estudo de indicadores de SSO. Foram excluídos relatos que:

- Dissertassem sobre uso de indicadores, mas em outras áreas de atuação, que não a de saúde e segurança ocupacional;

- Abordassem apenas metodologias para a construção indicadores, mas não citassem, de forma direta, estes indicadores;

- Tivessem foco em um setor de atividades específico;

- Citassem indicadores de SSO apenas como exemplos, não sendo o foco da pesquisa.

d) Inclusão

Para fins de inclusão na revisão sistemática, foram selecionados os artigos nos quais identificaram indicadores específicos da área da saúde e segurança ocupacional.

Os artigos incluídos, segundo a aplicação do Fluxograma PRISMA, compuseram o conjunto de indicadores proposto por este artigo.

Somou-se a estes KPIs os indicadores citados pela ABNT (2001), por serem considerados mandatórios nesta pesquisa (norma técnica oficial brasileira), e devido a sua contribuição no que tange a avaliação de desempenho de SSO. 
Survey

Este trabalho também utilizou o método de pesquisa survey, com amostragem não probabilística da população de interesse, com o objetivo de identificar a visão dos profissionais de SSO sobre a importância dos indicadores listados pela revisão sistemática da literatura, no auxílio à tomada de decisões.

A escolha do método survey ocorreu em função de ser uma forma aplicável de se obter acesso a dados ou informações sobre características, ações ou opiniões de determinado grupo de pessoas, por meio de um instrumento de pesquisa, normalmente um questionário (Tanur, 1982).

O questionário proposto foi constituído por perguntas fechadas e apresenta uma escala do tipo Likert com o objetivo de medir o grau de importância desses indicadores, para a tomada de decisões, segundo a percepção dos profissionais da área. A escala foi estruturada com cinco pontos de avaliação (1 - Sem importância 2 - Pouco importante, 3 - Razoavelmente importante, 4 - Importante, 5 - Muito importante).

\section{a) Amostragem da pesquisa}

A pesquisa utilizou amostragem por tipicidade. Segundo Vergara (2016), a amostragem por tipicidade é constituída pela seleção de elementos que o pesquisador considera representativos da população-alvo, o que requer profundo conhecimento dessa população (Vergara, 2016).

Desta forma, o pesquisador enviou o questionário para profissionais que atuam na área de saúde e segurança ocupacional, que serão os respondentes do questionário proposto nesta pesquisa.

\section{b) Sujeitos da Pesquisa}

Buscou-se indivíduos com experiência/conhecimento na área de saúde e segurança ocupacional, para a composição da amostra (Vergara, 2016).

Desta forma, para participação na presente pesquisa, os respondentes do questionário necessitaram cumprir os seguintes pré-requisitos:

- Possuir mais de cinco anos de experiência na área de saúde e segurança ocupacional;

- Possuir formação acadêmica na área de Saúde e Segurança Ocupacional.

\section{c) Pré teste}

Submeteu-se o questionário à análise de cinco profissionais de reconhecida experiência na área de SSO, conforme recomendado por Vergara (2016), aos quais foram solicitados que não só o preenchessem, como também exprimissem, por escrito, suas dúvidas ou outros comentários que se 
fizerem necessários. Posteriormente, procedeu-se às correções cabíveis, chegando-se à versão final do questionário.

d) Aplicação do questionário

O questionário foi elaborado através da ferramenta "Survey Monkey". Desta forma, o pesquisador enviou para os respondentes, via plataformas de redes sociais, o link de acesso à pesquisa, que permitiu aos participantes responderem ao questionário através de diversas plataformas (smartphones, tablets e computadores).

\section{Tratamento e análise dos dados}

Revisão Sistemática da Literatura

Após o mapeamento dos indicadores, os mesmos foram agrupados por similaridade e categorizados entre proativos e reativos, conforme conceituação de: Trethewy (2003); Robson et al. (2017), descritos no referencial teórico.

Em seguida a porcentagem de vezes em que os KPIs foram abordados pelos artigos mapeados foi calculada. Os KPIs citados em, no mínimo $20 \%$ dos artigos analisados, foram consolidados de forma a compor um questionário para apreciação de especialistas em SSO. Somou-se a estes KPIs os indicadores citados pela Associação Brasileira de Normas Técnicas (2001), por serem considerados mandatórios nesta pesquisa (norma técnica oficial brasileira), e devido a sua contribuição no que tange a avaliação de desempenho de SSO, mais especificamente nas medições reativas das consequências de acidentes e doenças ocupacionais.

Survey

Os dados obtidos na aplicação dos questionários foram considerados para compor o conjunto de indicadores proposto por este artigo. Nesse caso, a técnica de medição utilizada para estipular a regra de corte foi a frequência (Castanheira, 2013).

Assim sendo, após a aplicação do questionário, os indicadores considerados "Muito importantes", "Importantes" ou "Razoavelmente importantes" por mais de 80\% dos profissionais, foram considerados aptos a serem inseridos no conjunto de indicadores proposto.

Para se testar a confiabilidade da escala, dando maior robustez ao estudo, utilizou-se o coeficiente Alfa de Cronbach ( $\alpha$ de Cronbach) que, segundo Cortina (1993), é uma das ferramentas estatísticas mais importantes e difundidas em pesquisas envolvendo a construção de testes e sua aplicação. 
Ademais, a fim de apoiar e complementar os resultados relacionados aos objetivos específicos testou-se três conjecturas:

- Os indicadores selecionados na literatura são majoritariamente vistos como relevantes no "mundo real";

- Os indicadores reativos são mais relevantes do que os proativos;

- Experiência na área não afeta a percepção sobre a relevância dos indicadores selecionados na literatura.

A primeira conjectura testada necessitou da definição do significado de "majoritariamente vistos como relevantes". Definiu-se que um profissional considera os indicadores obtidos na literatura como majoritariamente relevantes se, pelo menos 20, dentre os 24 indicadores, são categorizados como Importantes ou Muito Importantes. Esta definição é conservadora pois requer que a ampla maioria dos indicadores sejam categorizados como Importantes ou Muito Importantes, apesar de que, tacitamente, observa-se que características idiossincráticas da área de aplicação podem afetar a escolha. Para testar a hipótese, definiu-se $\mathrm{P}$ a proporção de profissionais de saúde e segurança ocupacional que consideram os indicadores majoritariamente relevantes. A hipótese nula é $\mathrm{HO}: \mathrm{P}<=0,5$ enquanto a hipótese alternativa é $\mathrm{H} 1: \mathrm{P}>0,5$.

A segunda conjectura testada necessitou da definição de uma métrica para avaliar se o profissional considera os indicadores reativos mais relevantes do que os proativos. Para isso, calcula-se a moda das avaliações dos indicadores de cada tipo, obtendo um valor na mesma escala indicando 'nota' dada aos indicadores proativos e reativos. Utiliza-se o teste não paramétrico de Wilcoxon pareado para validar a hipótese.

$\mathrm{Na}$ terceira hipótese, os dados da primeira conjectura foram separados por tempo de experiência: Profissionais com tempo de experiência entre 5 e10 anos e profissionais com tempo de experiência maior do que 10 anos. Para analisar a dependência das variáveis utilizou-se o teste Quiquadrado.

O quadro 1 apresenta o resumo dos testes estatísticos realizados para análise das conjecturas apresentadas. 
Quadro 1

Resumo dos testes estatísticos propostos

\begin{tabular}{|l|l|l|}
\hline \multicolumn{1}{|c|}{ Conjectura } & \multicolumn{1}{|c|}{ Hipóteses } \\
\hline $\begin{array}{l}\text { Conjectura 1: Os indicadores } \\
\text { selecionados na literatura são } \\
\text { majoritariamente vistos como } \\
\text { relevantes no "mundo real” }\end{array}$ & $\begin{array}{l}\text { P= proporção de profissionais de saúde e } \\
\text { segurança ocupacional que consideram os } \\
\text { indicadores majoritariamente relevantes. } \\
\text { Hipótese nula -- H0: P <= 0.5; } \\
\text { Hipótese alternativa -- H1: P >0.5 }\end{array}$ & Teste Z \\
\hline $\begin{array}{l}\text { Conjectura 2: Os indicadores reativos } \\
\text { são mais relevantes do que os } \\
\text { proativos; }\end{array}$ & $\begin{array}{l}\text { M= Moda das avaliações dos indicadores de } \\
\text { cada tipo. } \\
\text { Hipótese nula -- H0: M reativos <= M } \\
\text { proativos; } \\
\text { Hipótese alternativa -- H1: M reativos > M } \\
\text { proativos }\end{array}$ & $\begin{array}{l}\text { Teste não } \\
\text { paramétrico de } \\
\text { Wilcoxon pareado }\end{array}$ \\
\hline $\begin{array}{l}\text { Conjectura 3: Experiência na área não } \\
\text { afeta a percepção sobre a relevância } \\
\text { dos indicadores selecionados na } \\
\text { literatura. }\end{array}$ & $\begin{array}{l}\text { Hipótese nula -- H0: variáveis são } \\
\text { independentes; } \\
\text { Hipótese alternativa -- H1: variáveis não são } \\
\text { independentes. }\end{array}$ & Teste Qui-quadrado \\
\hline
\end{tabular}

Fonte: Os autores.

\section{Análise e discussão dos resultados}

\section{Revisão Sistemática da Literatura}

As pesquisas realizadas nas bases de dados identificaram 4728 relatos sobre o tema. Restringiuse a busca aos títulos dos artigos, de forma a tornar viável a análise de todos os documentos e, desta forma, foi obtido um total de 78 textos.

Um relato foi identificado em outras fontes (ABNT, 2001), e foi incluída nesta pesquisa por ser uma norma técnica oficial brasileira, e devido a sua contribuição no que tange a avaliação de desempenho de SSO.

Após a eliminação dos trabalhos duplicados, foram selecionados 59 relatos que, ao passarem pela análise da leitura de títulos e resumos, diminuíram para 29 pesquisas potencialmente relevantes. Neste passo, dos 30 textos eliminados, 13 não possuíam foco na identificação de indicadores de SSO, 16 não tratava de assuntos relacionados ao tema, e 1 abordava indicadores de um setor específico.

A fase seguinte foi composta pela leitura na integra dos textos, resultando na eliminação de 19 relatos, observando-se que, destes 19, 11 artigos não demonstraram foco na identificação de indicadores de SSO e 2 tinham foco em um setor de atividades específico. Ademais, não foi possível encontrar ou ter acesso integral a 6 textos.

Assim sendo, após cumpridas as 4 etapas propostas pela adaptação da recomendação PRISMA, chegou-se a 10 documentos chave, dos quais foram levantados os indicadores para a composição do conjunto de KPIs proposto neste artigo. 
Os resultados gerados foram sistematizados e expostos na figura 2, utilizando-se para isso o fluxograma PRISMA.

\section{Figura 2}

\section{Fluxograma PRISMA aplicado à revisão sistemática da literatura}

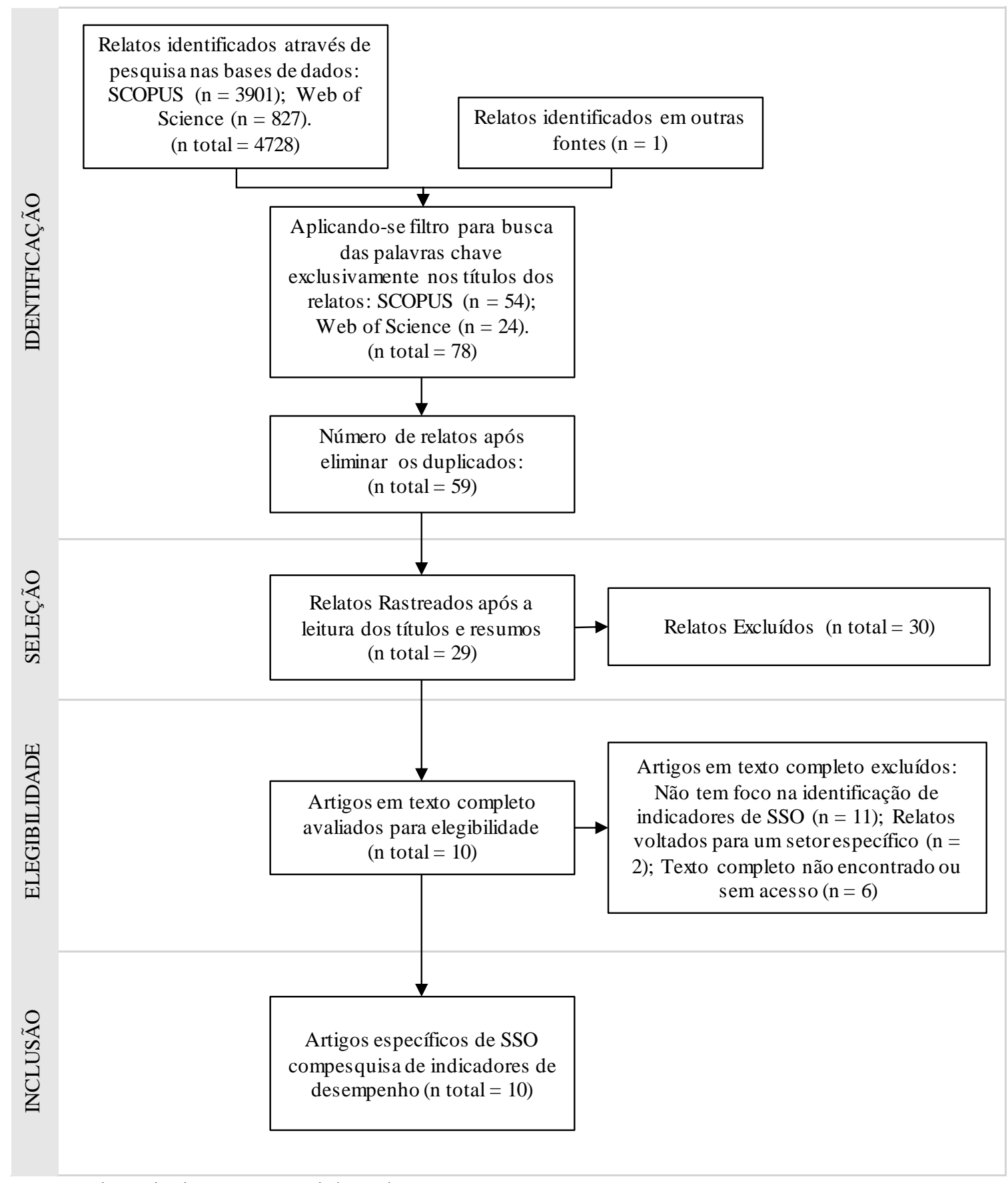

Fonte: Adaptado de MOHER et al. (2015) 
Segue abaixo os resumos dos principais pontos apresentados pelos 10 trabalhos incluídos na pesquisa.

- Dodsworth et al. (2007) - Produzir um modelo estatístico que pudesse ser usado para prever taxas significativas de frequência de lesões no local.

- Almeida, Nunes (2014) - Propor um conjunto de indicadores de avalição de desempenho para o Sistema de Gestão Ambiental e para o Sistemas de Gestão de Segurança e Saúde no Trabalho para uma organização.

- Podgórski (2015) - Realizar uma revisão da literatura sobre os principais indicadores de desempenho de segurança proativos.

- Egbevurie et al. (2016) - Discutir as contribuições de indicadores proativos em relação ao bom desempenho de Saúde Meio Ambiente e Segurança do Trabalho.

- Mohammadfam et al. (2017) - Avaliar o desempenho da OHSAS 18001 em uma organização.

- Gümüş, Gülsün (2017) - Analisar o status de segurança e saúde ocupacional da Turquia entre 1998 e 2014

- Korkusuz et al. (2018) - Investigar os principais indicadores de desempenho necessários para medir-se o desempenho em SSO.

- Lebeau et al. (2019) - Analisar o impacto que a extensão do prazo de vencimento dos dados de remuneração tem sobre os indicadores de SSO.

- Rudakov, Gridina, Ershov (2019) - Apresentar os resultados de pesquisas de potencial utilização do Índice de Segurança (Índice Elmeri).

- Associação Brasileira de Normas Técnicas (2001) - Fixar critérios para o registro, comunicação, estatística, investigação e análise de acidentes do trabalho, suas causas e consequências.

Vale salientar que nenhum dos trabalhos listados realizou a análise cruzada entre os indicadores listados pela literatura e uma survey respondida por profissionais da área.

Após a extração das informações contidas nos 10 documentos incluídos, realizou-se o mapeamento dos indicadores citados nos relatos, quando foram encontrados 120 indicadores de desempenho de SSO.

Os 120 indicadores listados foram categorizados entre Proativos e Reativos, conforme definição anteriormente definida no referencial teórico. Dentre os indicadores apontados, 90 (75\%) foram categorizados como proativos e 30 (25\%) como reativos.

A relação entre os 120 indicadores, suas referências bibliográficas e categorização entre proativos e reativos encontram-se no Apêndice $A$. 
Em seguida, os indicadores foram agrupados por similaridade, quando os KPIs citados em, no mínimo, 20\% dos artigos analisados, foram consolidados de forma a compor um questionário para apreciação de especialistas em SSO. Somou-se a estes KPIs os indicadores citados pela ABNT (2001), por serem considerados mandatórios nesta pesquisa (norma técnica oficial brasileira). Assim sendo, o questionário elaborado foi composto por 24 indicadores. O quadro 3 apresenta os 24 indicadores utilizados no questionário, classificados em ordem decrescente de frequência de aparição na literatura especializada.

\section{Quadro 2}

Indicadores utilizados no questionário e categorizados entre proativos e reativos

\begin{tabular}{|c|c|c|}
\hline Indicador & Frequência & Categorização \\
\hline Proporção de trabalhadores treinados & $40 \%$ & Proativo \\
\hline Nível de Informação dos funcionários & $30 \%$ & Proativo \\
\hline Comportamento inseguro observado & $30 \%$ & Reativo \\
\hline Taxa de Frequência de Acidentes & $\begin{array}{c}30 \% \\
*\end{array}$ & Reativo \\
\hline $\mathrm{N}^{\mathrm{o}}$ de políticas de SSO que foram revistas & $20 \%$ & Proativo \\
\hline $\mathrm{N}^{\mathrm{o}}$ de melhorias em SSO propostas pelos trabalhadores & $20 \%$ & Proativo \\
\hline $\mathrm{N}^{\mathrm{o}}$ de reuniões realizadas com trabalhadores sobre questões de SSO & $20 \%$ & Proativo \\
\hline $\mathrm{N}^{\mathrm{o}}$ de horas de treinamento em SSO por pessoa & $20 \%$ & Proativo \\
\hline $\begin{array}{l}N^{o} \text { de edições do boletim de SSO da empresa ou outras publicações internas de } \\
\text { SSO }\end{array}$ & $20 \%$ & Proativo \\
\hline $\mathrm{N}^{\mathrm{o}}$ de quase acidentes & $20 \%$ & Reativo \\
\hline $\mathrm{N}^{\mathrm{o}}$ de eventos de SSO para funcionários & $20 \%$ & Proativo \\
\hline $\mathrm{N}^{\mathrm{o}}$ de não conformidades totais do SGSSO & $20 \%$ & Reativo \\
\hline $\begin{array}{l}\text { Porcentagem de locais de trabalho com avaliação de risco verificada no decorrer } \\
\text { da introdução de novas máquinas, materiais, mudança de método de trabalho } \\
\text { etc. }\end{array}$ & $20 \%$ & Proativo \\
\hline $\begin{array}{l}\text { Porcentagem de requisitos de SSO verificados periodicamente e aplicados nas } \\
\text { especificações de compra }\end{array}$ & $20 \%$ & Proativo \\
\hline $\begin{array}{l}\mathrm{N}^{\mathrm{o}} \text { de ações corretivas e preventivas realizadas como resultado de análises de } \\
\text { causa raiz de acidentes, doenças e incidentes relacionados ao trabalho }\end{array}$ & $20 \%$ & Proativo \\
\hline Proporção de verificações periódicas & $20 \%$ & Proativo \\
\hline Índice de custos totais com o SGSSO & $20 \%$ & Proativo \\
\hline Porcentagem de funcionários informados sobre a política de SSO & $20 \%$ & Proativo \\
\hline $\begin{array}{l}\mathrm{N}^{\mathrm{o}} \text { de acidentes de trabalho ocorridos na empresa/ } \mathrm{N}^{\mathrm{o}} \text { de funcionários dentro do } \\
\text { período considerado. }\end{array}$ & $20 \%$ & Reativo \\
\hline Taxa de Frequência de Acidentes Fatais & $20 \%$ & Reativo \\
\hline Condições inseguras observadas & $20 \%$ & Reativo \\
\hline Taxa de Frequência de acidentado com lesão com afastamento & $20 \% *$ & Reativo \\
\hline Taxa de Gravidade & $10 \% *$ & Reativo \\
\hline Taxa de Frequência de acidentado com lesão sem afastamento & $10 \% *$ & Reativo \\
\hline
\end{tabular}

Fonte: Os autores. * Indicador citado pela ABNT (2001) 
Survey

O questionário proposto para avaliação da relevância dos indicadores, segundo a percepção dos profissionais de SSO, foi respondido por 60 especialistas, dos quais, 1 (1,67\%) possuía de 1 a 5 anos de experiência na área, 26 (43,33\%) possuíam entre 5 e 10 anos, 15 (25\%) possuíam entre 10 e 15 anos e 18 (30\%) possuíam mais de 15 anos de experiência na área de SSO. Vale ressaltar que não houve respondentes com menos de 1 ano de experiência na área.

No que tange a formação acadêmica, dos 60 respondentes 18 (30\%) eram Técnicos de Segurança do Trabalho, 17 (28,33\%) eram Engenheiros de Segurança do Trabalho, 17 (28,33\%) eram Médicos do Trabalho, 4 (6,67\%) Enfermeiros do Trabalho e 4 (6,67\%) em auxiliar de Enfermagem.

Todos os especialistas responderam a todas as perguntas do questionário. As respostas de 1 (um) especialista não foram consideradas, visto que ele não atendeu a um dos critérios estabelecidos para a pesquisa (possuir mais de 5 anos de experiência). Desta forma, o número final de respondentes habilitados foi 59.

Os profissionais habilitados a responderem a pesquisa classificaram os indicadores através de uma escala do tipo Likert, em 5 níveis (Muito Importante, Importante, Razoavelmente Importante, Pouco Importante e Sem importância). Os dados obtidos após a análise destas respostas encontram-se no quadro 4. 


\section{Quadro 3}

Categorização dos indicadores conforme a percepção dos profissionais

\begin{tabular}{|c|c|c|c|c|c|c|}
\hline \multirow[b]{2}{*}{ Indicadores } & \multicolumn{5}{|c|}{ Classificação dos Especialistas } & \multirow[b]{2}{*}{$\begin{array}{c}\text { Somatório: } \\
\text { Muito } \\
\text { Importante, } \\
\text { Importante e } \\
\text { Razoavelmente } \\
\text { Importante. }\end{array}$} \\
\hline & 욜 & 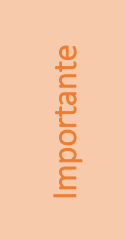 & 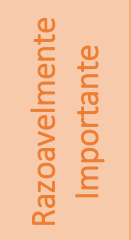 & 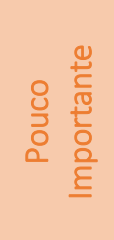 & 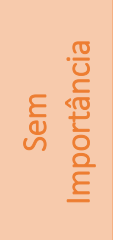 & \\
\hline № de horas de treinamento em SSO por pessoa. & $37,29 \%$ & $40,68 \%$ & $22,03 \%$ & $0,00 \%$ & $0,00 \%$ & $100,00 \%$ \\
\hline Comportamento inseguro observado & $35,59 \%$ & $49,15 \%$ & $15,26 \%$ & $0,00 \%$ & $0,00 \%$ & $100,00 \%$ \\
\hline Condições inseguras observadas: & $55,93 \%$ & $32,21 \%$ & $11,86 \%$ & $0,00 \%$ & $0,00 \%$ & $100,00 \%$ \\
\hline $\begin{array}{l}\text { № de eventos de SSO realizados para os } \\
\text { funcionários. }\end{array}$ & $42,37 \%$ & $44,07 \%$ & $13,56 \%$ & $0,00 \%$ & $0,00 \%$ & $100,00 \%$ \\
\hline $\begin{array}{l}\text { № de ações corretivas e preventivas realizadas } \\
\text { como resultado de análises de causa raiz de } \\
\text { acidentes, doenças e incidentes relacionados ao } \\
\text { trabalho. }\end{array}$ & $64,41 \%$ & $32,20 \%$ & $3,39 \%$ & $0,00 \%$ & $0,00 \%$ & $100,00 \%$ \\
\hline Taxa de Frequência de Acidentes Fatais & $74,58 \%$ & $13,56 \%$ & $10,17 \%$ & $0,00 \%$ & $1,69 \%$ & $98,31 \%$ \\
\hline Taxa de Gravidade & $54,24 \%$ & $33,90 \%$ & $10,17 \%$ & $0,00 \%$ & $1,69 \%$ & $98,31 \%$ \\
\hline Proporção de verificações periódicas & $35,59 \%$ & $44,07 \%$ & $18,64 \%$ & $1,69 \%$ & $0,00 \%$ & $98,31 \%$ \\
\hline № de quase acidentes ocorridos na empresa. & $49,15 \%$ & $44,07 \%$ & $5,08 \%$ & $1,69 \%$ & $0,00 \%$ & $98,31 \%$ \\
\hline Proporção de trabalhadores treinados & $54,24 \%$ & $32,20 \%$ & $11,86 \%$ & $1,69 \%$ & $0,00 \%$ & $98,31 \%$ \\
\hline $\begin{array}{l}\text { № de melhorias em SSO propostas pelos } \\
\text { trabalhadores. }\end{array}$ & $59,32 \%$ & $33,90 \%$ & $5,08 \%$ & $1,69 \%$ & $0,00 \%$ & $98,31 \%$ \\
\hline $\begin{array}{l}\text { Porcentagem de locais de trabalho com } \\
\text { avaliação de risco verificada no decorrer da } \\
\text { introdução de novas máquinas, materiais, } \\
\text { mudança de método de trabalho etc. }\end{array}$ & $38,98 \%$ & $54,24 \%$ & $5,08 \%$ & $1,69 \%$ & $0,00 \%$ & $98,31 \%$ \\
\hline $\begin{array}{l}\text { Taxa de Frequência de acidentado com lesão } \\
\text { com afastamento }\end{array}$ & $62,71 \%$ & $30,51 \%$ & $3,39 \%$ & $1,69 \%$ & $1,69 \%$ & $96,61 \%$ \\
\hline $\begin{array}{l}\text { Nível de Informação dos funcionários, sobre } \\
\text { SSO. }\end{array}$ & $61,02 \%$ & $32,20 \%$ & $3,39 \%$ & $1,69 \%$ & $1,69 \%$ & $96,61 \%$ \\
\hline $\begin{array}{l}\text { Porcentagem de requisitos de SSO verificados } \\
\text { periodicamente e aplicados nas especificações } \\
\text { de compra. }\end{array}$ & $27,12 \%$ & $47,46 \%$ & $22,03 \%$ & $3,39 \%$ & $0,00 \%$ & $96,61 \%$ \\
\hline Taxa de Frequência de Acidentes & $55,93 \%$ & $38,98 \%$ & $1,69 \%$ & $1,69 \%$ & $1,69 \%$ & $96,61 \%$ \\
\hline $\begin{array}{l}\text { Índice de custos totais com o Sistema de Gestão } \\
\text { de SSO. }\end{array}$ & $33,90 \%$ & $44,07 \%$ & $18,64 \%$ & $3,39 \%$ & $0,00 \%$ & $96,61 \%$ \\
\hline $\begin{array}{l}\text { № de reuniões realizadas com trabalhadores } \\
\text { sobre questões de SSO. }\end{array}$ & $23,73 \%$ & $52,54 \%$ & $18,64 \%$ & $5,08 \%$ & $0,00 \%$ & $94,92 \%$ \\
\hline $\begin{array}{l}\text { Taxa de Frequência de acidentado com lesão } \\
\text { sem afastamento }\end{array}$ & $45,76 \%$ & $45,76 \%$ & $3,39 \%$ & $3,39 \%$ & $1,69 \%$ & $94,92 \%$ \\
\hline $\begin{array}{l}\text { № de não conformidades totais do Sistema de } \\
\text { Gestão de SSO. }\end{array}$ & $45,76 \%$ & $44,07 \%$ & $5,08 \%$ & $5,08 \%$ & $0,00 \%$ & $94,92 \%$ \\
\hline $\begin{array}{l}\text { Porcentagem de funcionários informados sobre } \\
\text { a política de SSO. }\end{array}$ & $62,71 \%$ & $23,73 \%$ & $8,47 \%$ & $3,39 \%$ & $1,69 \%$ & $94,92 \%$ \\
\hline
\end{tabular}




\begin{tabular}{|c|c|c|c|c|c|c|}
\hline Indicadores & \multicolumn{5}{|c|}{ Classificação dos Especialistas } & \multirow{2}{*}{$\begin{array}{l}\text { Somatório: } \\
\text { Muito } \\
\text { Importante, } \\
\text { Importante e } \\
\text { Razoavelmente } \\
\text { Importante. } \\
\text { 94,92\% }\end{array}$} \\
\hline $\begin{array}{l}\text { № de acidentes de trabalho ocorridos na } \\
\text { empresa/ № de funcionários dentro do período } \\
\text { considerado. }\end{array}$ & $62,71 \%$ & $30,51 \%$ & $1,69 \%$ & $5,08 \%$ & $0,00 \%$ & \\
\hline № de políticas de SSO que foram revistas. & $20,34 \%$ & $42,37 \%$ & $25,42 \%$ & $10,17 \%$ & $1,69 \%$ & $88,14 \%$ \\
\hline $\begin{array}{l}\text { № de edições do boletim de SSO da empresa ou } \\
\text { outras publicações internas de SSO. }\end{array}$ & $10,17 \%$ & $37,29 \%$ & $38,98 \%$ & $10,17 \%$ & $3,39 \%$ & $86,44 \%$ \\
\hline
\end{tabular}

Fonte: Os autores.

Desta forma, após a análise dos questionários respondidos pelos especialistas, constituídos pelos 24 indicadores mais frequentemente citados pela literatura especializada, pode-se constatar que todos os KPIs apresentados foram considerados relevantes para a tomada de decisão em SSO, de acordo com a percepção da maioria dos profissionais.

Para se testar a confiabilidade da escala, dando maior robustez ao estudo, utilizou-se o auxílio do coeficiente Alfa de Cronbach. A aplicação desse teste demonstrou um resultado de 0,88, confirmando que o questionário aplicado possui uma adequada confiabilidade interna, conforme classificação de Cronbach (1951).

A estatística utilizada para apoiar e complementar os objetivos específicos testou três conjecturas:

- Os indicadores selecionados na literatura são majoritariamente vistos como relevantes no "mundo real";

- Os indicadores reativos são mais relevantes do que os proativos;

- Experiência na área não afeta a percepção sobre a relevância dos indicadores selecionados na literatura.

Para testar a hipótese, definiu-se $\mathrm{P}$ a proporção de profissionais de saúde e segurança ocupacional que consideram os indicadores majoritariamente relevantes. A hipótese nula é $\mathrm{HO}: \mathrm{P}<=0,5$ enquanto a hipótese alternativa é $\mathrm{H} 1: \mathrm{P}>0,5$.

A hipótese acima foi testada utilizando os dados da pesquisa feita com profissionais da área, que foi suposta uma amostra aleatória. Observou-se que 43, dentre os 59 pesquisados consideram indicadores majoritariamente relevantes. A estatística de teste $z=(34 / 59-0,5) /\left(\backslash \operatorname{sqrt}\left(0,5^{*} 0,5 / 59\right)=\right.$ 3,515, que corresponde a um p-valor 0.0002. Logo, obtemos evidências de que a maioria dos profissionais da área, de fato, considera os indicadores selecionados na literatura como majoritariamente relevantes, uma vez que se rejeitou a hipótese nula a um nível de significância de 5\%. 
Para a validação da hipótese relacionada à segunda conjectura utilizou-se o teste não paramétrico de Wilcoxon pareado. Sob a hipótese alternativa de que indicadores reativos são melhores avaliados, o teste retornou um p-valor de 0,254. Logo, verificou-se que não há evidências para afirmar que os profissionais consideram indicadores reativos mais relevantes a um nível de significância de 5\%. De fato, foi possível mostrar que não há evidências para dizer que um ou outro é mais relevante. Realizando o mesmo teste, porém bicaudal, isto é, a hipótese alternativa é que a nota dada a indicadores reativos e proativos é distinta, obteve-se um p-valor 0,509.

Para testar a hipótese relacionada a terceira conjectura observou-se a distribuição exibida no quadro 5.

\section{Quadro 4}

Categorização da relevância dos indicadores considerando o tempo de experiência dos profissionais

\begin{tabular}{|c|c|c|c|}
\hline \multirow{2}{*}{ Categorização } & \multicolumn{3}{|c|}{ Tempo de Experiência } \\
\hline & Entre 5 e 10 anos & Mais de 10 anos & Total \\
\hline Relevantes & 20 & 23 & 43 \\
\hline Não Relevantes & 6 & 10 & 16 \\
\hline Total & 26 & 33 & 59 \\
\hline
\end{tabular}

Fonte: Elaboração própria.

Usando o teste Qui-quadrado para independência entre experiência e qualificar relevância de indicadores, obteve-se um p-valor de 0,5354, o que indica que não foram identificadas evidências para indicar dependência entre as variáveis a um nível de significância de 5\%. Portanto, a experiência não altera as conclusões obtidas anteriormente e, logo, os indicadores são considerados relevantes, independentemente do tempo de experiência do profissional.

O quadro 6 apresenta os testes estatísticos realizados. 
Quadro 5

Testes estatísticos

\begin{tabular}{|c|c|c|c|c|c|}
\hline Conjectura & Dados & Hipótese nula & p-valor & $\begin{array}{l}\text { Resultado } \\
\text { do Teste }\end{array}$ & $\begin{array}{l}\text { Análise da } \\
\text { conjectura }\end{array}$ \\
\hline $\begin{array}{l}\text { Os indicadores } \\
\text { selecionados na } \\
\text { literatura são } \\
\text { majoritariamente } \\
\text { vistos como } \\
\text { relevantes no } \\
\text { "mundo real" }\end{array}$ & $\begin{array}{l}\text { Definiu-se que um } \\
\text { profissional } \\
\text { considera os } \\
\text { indicadores obtidos } \\
\text { na literatura como } \\
\text { majoritariamente } \\
\text { relevantes se, pelo } \\
\text { menos } 20 \text {, dentre } \\
\text { os } 24 \text { indicadores, } \\
\text { são categorizados } \\
\text { como Importantes } \\
\text { ou Muito } \\
\text { Importantes. }\end{array}$ & $\begin{array}{l}\mathrm{P}=\text { proporção de } \\
\text { profissionais de } \\
\text { saúde e } \\
\text { segurança } \\
\text { ocupacional que } \\
\text { consideram os } \\
\text { indicadores } \\
\text { majoritariamente } \\
\text { relevantes. } \\
\text { Hipótese nula -- } \\
\text { H0: } \mathrm{P}<=0.5 ; \\
\text { Hipótese } \\
\text { alternativa -- } \mathrm{H} 1 \text { : } \\
\mathrm{P}>0.5\end{array}$ & 0,0002 & $\begin{array}{l}\text { Existem } \\
\text { evidências } \\
\text { para rejeitar } \\
\text { a hipótese } \\
\text { nula. }\end{array}$ & $\begin{array}{l}\text { Maioria dos } \\
\text { profissionais } \\
\text { considera } \\
\text { indicadores } \\
\text { selecionados na } \\
\text { literatura como } \\
\text { majoritariamente } \\
\text { relevantes }\end{array}$ \\
\hline $\begin{array}{l}\text { Os indicadores } \\
\text { reativos são mais } \\
\text { relevantes do } \\
\text { que os proativos; }\end{array}$ & $\begin{array}{l}\text { Calcula-se a moda } \\
\text { das avaliações dos } \\
\text { indicadores de cada } \\
\text { tipo, obtendo um } \\
\text { valor na mesma } \\
\text { escala indicando } \\
\text { 'nota' dada aos } \\
\text { classificadores } \\
\text { proativos e reativos }\end{array}$ & $\begin{array}{l}\text { M = Moda das } \\
\text { avaliações dos } \\
\text { indicadores de } \\
\text { cada tipo. } \\
\text { Hipótese nula -- } \\
\text { HO: M reativos } \\
<=\text { M proativos; } \\
\text { Hipótese } \\
\text { alternativa -- H1: } \\
\text { M reativos > M } \\
\text { proativos }\end{array}$ & 0,254 & $\begin{array}{l}\text { Não existem } \\
\text { evidências } \\
\text { para rejeitar } \\
\text { a hipótese } \\
\text { nula. }\end{array}$ & $\begin{array}{l}\text { Não foram } \\
\text { identificadas } \\
\text { evidências para } \\
\text { afirmar que os } \\
\text { profissionais } \\
\text { consideram } \\
\text { indicadores reativos } \\
\text { mais relevantes do } \\
\text { que os proativos. }\end{array}$ \\
\hline $\begin{array}{l}\text { Experiência na } \\
\text { área não afeta a } \\
\text { percepção sobre } \\
\text { a relevância dos } \\
\text { indicadores } \\
\text { selecionados na } \\
\text { literatura. }\end{array}$ & $\begin{array}{l}\text { Definiu-se que um } \\
\text { profissional } \\
\text { considera os } \\
\text { indicadores obtidos } \\
\text { na literatura como } \\
\text { majoritariamente } \\
\text { relevantes se, pelo } \\
\text { menos 20, dentre } \\
\text { os } 24 \text { indicadores, } \\
\text { são categorizados } \\
\text { como Importantes } \\
\text { ou Muito } \\
\text { Importantes. } \\
\text { Separamos os } \\
\text { dados em 5-10 } \\
\text { anos de experiência } \\
\text { e mais do que } 10 \\
\text { anos de } \\
\text { experiência. }\end{array}$ & $\begin{array}{l}\text { Teste chi- } \\
\text { quadrado para } \\
\text { independência. } \\
\text { hipótese nula -- } \\
\text { H0: variáveis são } \\
\text { independentes } \\
\text { hipótese } \\
\text { alternativa -- H1: } \\
\text { variáveis não são } \\
\text { independentes }\end{array}$ & 0,5354 & $\begin{array}{l}\text { Não rejeita } \\
\text { HO. } \\
\text { Não existem } \\
\text { evidências } \\
\text { de } \\
\text { dependência } \\
\text { entre as } \\
\text { variáveis. }\end{array}$ & $\begin{array}{l}\text { Os indicadores são } \\
\text { considerados } \\
\text { relevantes, } \\
\text { independentemente } \\
\text { do tempo de } \\
\text { experiência do } \\
\text { profissional. }\end{array}$ \\
\hline
\end{tabular}

Fonte: Os autores. 
A presente pesquisa buscou contribuir com o processo de tomada de decisões em Saúde e Segurança Ocupacional em organizações brasileiras através da identificação de um conjunto de $24 \mathrm{KPIS}$ listados pela literatura especializada e confirmados como relevantes pelos profissionais da área de SSO.

Para o atingimento do objetivo da pesquisa, inicialmente se mapeou, através de uma revisão sistemática da literatura, os indicadores de SSO utilizados para as tomadas de decisões na área. Nesse sentido o trabalho analisou diversas pesquisas realizadas sobre o tema e consolidou 120 indicadores citados pela literatura nacional e internacional. Este mapeamento pode ser considerado de grande valia para que gestores e pesquisadores, de diversos seguimentos, possuam uma relevante base de consulta de indicadores de desempenho utilizando-os de acordo com a realidade de suas organizações.

Esses indicadores foram ainda categorizados entre proativos e reativos e pôde-se observar que os categorizados como proativo são mais frequentemente citados pela bibliografia (75\%) confirmando a tendência trazida pelo referencial teórico. De forma complementar, indicadores reativos também foram apresentados pelo estudo de modo a auxiliar os tomadores de decisões no entendimento das consequências das doenças e acidentes ocorridos, possibilitando assim, o planejamento de estratégias voltadas para a melhoria de SSO da sua organização.

Após análise de frequência das citações dos 120 indicadores listados pela literatura, chegou-se a um conjunto de 24 KPIs. Em seguida, a relevância destes KPIs foi avaliada por 59 profissionais de SSO, quando identificou-se que estes indicadores são considerados relevantes por mais de $80 \%$ destes especialistas. Este conjunto, elaborado através do relacionamento entre literatura e prática, pode auxiliar os tomadores de decisão quanto à escolha dos indicadores a serem utilizados em suas organizações, além de contribuir para o aumento do conhecimento sobre o tema.

De forma complementar, a pesquisa verificou que não existem evidências estatísticas para constatar que um tipo de indicador (proativo / reativo) é mais relevante do que o outro. A pesquisa constatou ainda que o tempo de experiência dos profissionais de SSO não afeta sua percepção sobre a relevância dos indicadores.

Como recomendações para estudos futuros, sugere-se a realização de estudos de casos que venham a analisar a relação entre a utilização do conjunto de indicadores apresentados por este estudo e a melhoria da eficiência dos processos das organizações estudadas.

Como limitações da pesquisa, vale ressaltar que as fontes utilizadas para a pesquisa bibliográfica ficam limitada às bases de consulta utilizadas pelo pesquisador. Ademais, ao utilizar um processo de categorização semântica para a realização da revisão da literatura, incorre-se na possibilidade de erro na compreensão exata do sentido das informações extraídas dos artigos. 


\section{Referências}

Almeida, C. L., \& Nunes, A. B. D. A. (2014). Proposta de indicadores para avaliação de desempenho dos Sistemas de Gestão Ambiental e de Segurança e Saúde no Trabalho de Empresas do ramo de engenharia consultiva. Gestão \& Produção, 21(4), 810-820. https://doi.org/10.1590/0104$530 \times 649$

Associação Brasileira de Normas Técnicas. (2001). NBR-14280: cadastro de acidente do trabalhoprocedimento e classificação.

Castanheira, N. P (2013). Estatística aplicada a todos níveis. Editora Intersaberes.

Cortina, J. M. (1993). What is coefficient alpha? An examination of theory and applications. Journal of applied psychology, 78(1), 98. https://doi.org/10.1037/0021-9010.78.1.98

Cronbach, L. J. (1951). Coefficient alpha and the internal structure of tests. psychometrika, 16(3), $297-$ 334. https://doi.org/10.1007/BF02310555

Dodsworth, M., Connelly, K. E., Ellett, C. J., \& Sharratt, P. (2007). Organizational climate metrics as safety, health and environment performance indicators and an aid to relative risk ranking within industry. Process Safety and Environmental Protection, 85(1), 59-69. https://doi.org/10.1205/psep06006

Egbevurie, B., Mustapha, A., Chine, O., \& Amadi, A. (2016, October). Promoting Safe Work Environment and Good HSE Culture by Reporting Leading Indicators: Case Study in Oil \& Gas Industry. In SPE African Health, Safety, Security, Environment, and Social Responsibility Conference and Exhibition. Society of Petroleum Engineers. https://doi.org/10.2118/183568MS 
Galindo, C. A. C., \& Monge, E. L. P. (2018, June). Business intelligence: Evaluation of occupational risks using a dashboard focused on decision making. In 2018 13th Iberian Conference on Information Systems and Technologies (CISTI) (pp. 1-4). IEEE. https://doi.org/10.23919/CISTI.2018.8399345

Guarda, T., León, M., Augusto, M. F., Pinto, F. M., Barrionuevo, O., \& Villao, D. (2018). Pervasive Business Intelligence: A Key Success Factor for Business. In Developments and Advances in Intelligent Systems and Applications (pp. 81-89). Springer, Cham. https://doi.org/10.1007/9783-319-58965-7_6

Gümüş, R., \& Gülsün, Z. (2017). Occupational health and safety indicators of Turkey and their relationships with social and economic development factors between 1998 and 2014. International Journal of Healthcare Management, 1-9. http://dx.doi.org/10.1080/20479700.2017.1308669

Luyten, J., Steel, J., \& Godderis, L. (2017). Economic evaluation of occupational health services: necessary, challenging and promising. Occupational and Environmental Medicine, 74(11), 847848. http://dx.doi.org/10.1136/oemed-2017-104495

Mansoori, B., Novak, R. D., Sivit, C. J., \& Ros, P. R. (2013). Utilization of dashboard technology in academic radiology departments: results of a national survey. Journal of the American College of Radiology, 10(4), 283-288. https://doi.org/10.1016/j.jacr.2012.09.030

Miler, M., Gabaj, N. N., Dukic, L., \& Simundic, A. M. (2018). Key performance indicators to measure improvement after implementation of total laboratory automation Abbott Accelerator a3600. Journal of medical systems, 42(2), 28. https://doi.org/10.1007/s10916-017-0878-1 
Mohammadfam, I., Kamalinia, M., Momeni, M., Golmohammadi, R., Hamidi, Y., \& Soltanian, A. (2017). Evaluation of the quality of occupational health and safety management systems based on key performance indicators in certified organizations. Safety and health at work, 8(2), 156-161. https://doi.org/10.1016/j.shaw.2016.09.001

Moher, D., Shamseer, L., Clarke, M., Ghersi, D., Liberati, A., Petticrew, M., ... \& Stewart, L. A. (2015). Preferred reporting items for systematic review and meta-analysis protocols (PRISMA-P) 2015 statement. Systematic reviews, 4(1), 1. https://doi.org/10.1186/2046-4053-4-1

Nagyova, A., \& Pacaiova, H. (2009). How to build manual for key performance indicators--KPI. DAAAM International Scientific Book, 135-143. https://doi.org/10.2507/daaam.scibook.2009.15

Podgórski, D. (2015). Measuring operational performance of OSH management system-A demonstration of AHP-based selection of leading key performance indicators. Safety science, 73, 146-166. https://doi.org/10.1016/j.ssci.2014.11.018

Robson, L. S., Ibrahim, S., Hogg-Johnson, S., Steenstra, I. A., Van Eerd, D., \& Amick III, B. C. (2017). Developing leading indicators from OHS management audit data: Determining the measurement properties of audit data from the field. Journal of safety research, 61, 93-103. https://doi.org/10.1016/j.jsr.2017.02.008

Rudakov, M. L., Gridina, E. B., \& Ershov, V. S. (2019). Utilisation of the Safety Index (Elmeri Index) as the OSH Indicator at Coal Mines. Latvian Journal of Physics and Technical Sciences, 56(3), 2636. https://doi.org/10.2478/lpts-2019-0017

Sandes, A. D. S. T., \& Loos, M. J. (2019). Implementação de uma rotina de acompanhamento de indicadores de performance como base para a tomada de decisão. Exacta, 17(2), 1-16. 
Salles, J. A. A., \& lozzi, L. O. (2010). Contribuições para a configuração de um sistema de medição de desempenho para incubadoras de empresas baseado no BSC. Exacta, 8(2), 145-156. https://doi.org/10.5585/exacta.v8i2.1994

Steel, J., Godderis, L., \& Luyten, J. (2018). Methodological challenges in the economic evaluation of occupational health and safety programmes. International journal of environmental research and public health, 15(11), 2606. https://doi.org/10.3390/ijerph15112606

Tanur, J. M. (1982). Advances in methods for large-scale surveys and experiments. Five Year Outlook on Science and Technology, 589-619.

Trethewy, R. W. (2003). OHS PERFORMANCE-IMPROVED INDICATORS FOR CONSTRUCTION CONTRACTORS. Journal of Construction Research, 4(01), 17-27. https://doi.org/10.1142/S1609945103000261

Vergara, S. C. Projetos e relatórios de pesquisa em administração. (2016). São Paulo: Atlas.

Yang, G., Macnab, A., Yang, L., \& Fan, C. (2015). Developing performance measures and setting their targets for national research institutes based on strategy maps. Journal of Science \& Technology Policy Management. https://doi.org/10.1108/JSTPM-12-2014-0042

Apêndice A - Relação entre indicadores, referências bibliográficas e categorização (proativos e reativos) 


\begin{tabular}{|c|c|c|c|c|c|c|c|c|c|c|c|}
\hline & 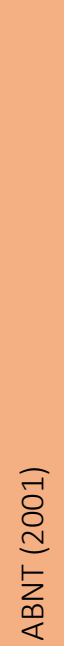 & 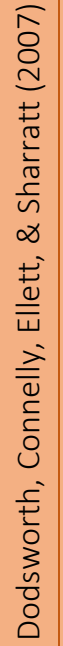 & 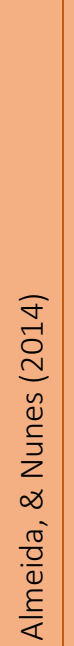 & 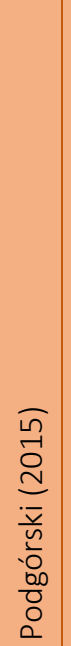 & 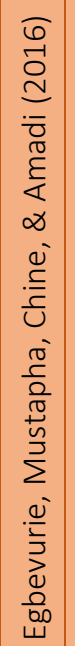 & 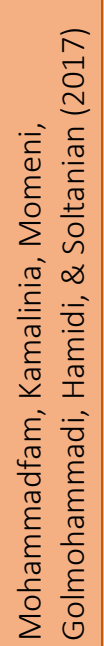 & 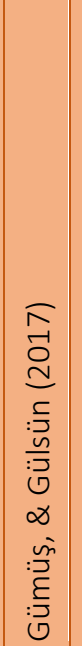 & 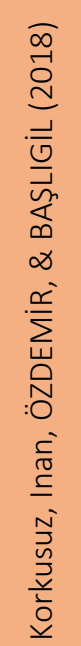 & 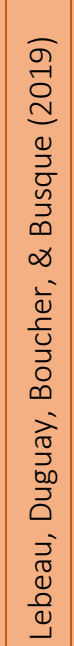 & 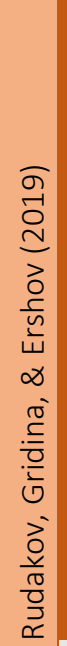 & \\
\hline Taxa de Gravidade & $x$ & & & & & & & & & & Reativo \\
\hline Taxa de Frequência de Acidentes & $x$ & & & & & & & & & & Reativo \\
\hline $\begin{array}{l}\text { Taxa de Frequência de acidentes com } \\
\text { lesão com afastamento }\end{array}$ & $x$ & & & & & & & & & & Reativo \\
\hline $\begin{array}{l}\text { Taxa de Frequência de acidentes com } \\
\text { lesão sem afastamento }\end{array}$ & $x$ & & & & & & & & & & Reativo \\
\hline Clima Organizacional de segurança & & $x$ & & & & & & & & & Proativo \\
\hline Índice de metas do SGSST atingidas & & & $x$ & & & & & & & & Proativo \\
\hline Índice de avaliações ergonômicas & & & $x$ & & & & & & & & Proativo \\
\hline Índice de objetivos atingidos do SGSST & & & $x$ & & & & & & & & Proativo \\
\hline Índice de custos totais com o SGSST & & & $x$ & & & & & & & & Proativo \\
\hline $\begin{array}{l}\text { Índice de treinamentos de Saúde e } \\
\text { Segurança do Trabalho (SST) }\end{array}$ & & & $\mathrm{x}$ & & & & & & & & Proativo \\
\hline $\begin{array}{l}\text { № de eventos de sensibilização para } \\
\text { assuntos de SST realizados }\end{array}$ & & & $x$ & & & & & & & & Proativo \\
\hline Nível de Informação dos funcionários & & & $x$ & & & & & & & & Proativo \\
\hline $\begin{array}{l}\text { Índice de participação em eventos } \\
\text { organizados pelo setor de SSO }\end{array}$ & & & $x$ & & & & & & & & Proativo \\
\hline Índice de rotatividade & & & $x$ & & & & & & & & Proativo \\
\hline $\begin{array}{l}\text { № de afastamentos por doenças } \\
\text { laborais/ № de funcionários }\end{array}$ & & & $\mathrm{x}$ & & & & & & & & Reativo \\
\hline $\begin{array}{l}\text { № de acidentes de trabalho ocorridos } \\
\text { na empresa/ № de funcionários }\end{array}$ & & & $x$ & & & & & & & & Reativo \\
\hline $\begin{array}{l}\text { № de não conformidades totais do } \\
\text { SGSST }\end{array}$ & & & $x$ & & & & & & & & Reativo \\
\hline $\begin{array}{l}\text { № de revisões e atualizações de } \\
\text { políticas de SST realizadas pela alta } \\
\text { gerência }\end{array}$ & & & & $x$ & & & & & & & Proativo \\
\hline $\begin{array}{l}\text { Porcentagem de trabalhadores que } \\
\text { declaram bons conhecimentos da } \\
\text { política de SST }\end{array}$ & & & & $\mathrm{x}$ & & & & & & & Proativo \\
\hline $\begin{array}{l}\text { № de orientações de segurança } \\
\text { realizadas pela alta gerência }\end{array}$ & & & & $x$ & & & & & & & Proativo \\
\hline $\begin{array}{l}\text { № de melhorias em SST propostas } \\
\text { pelos trabalhadores }\end{array}$ & & & & $x$ & & & & & & & Proativo \\
\hline
\end{tabular}




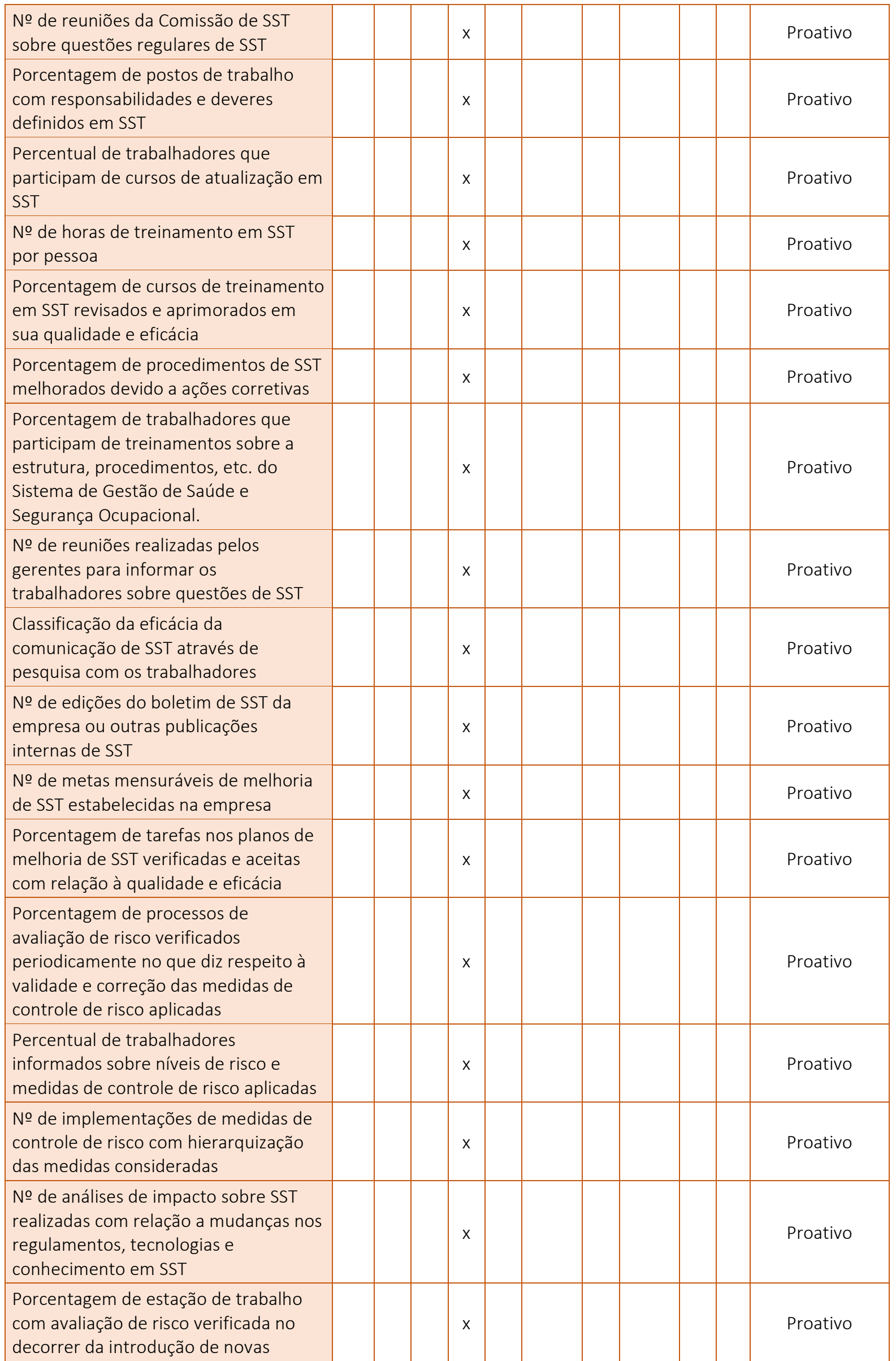




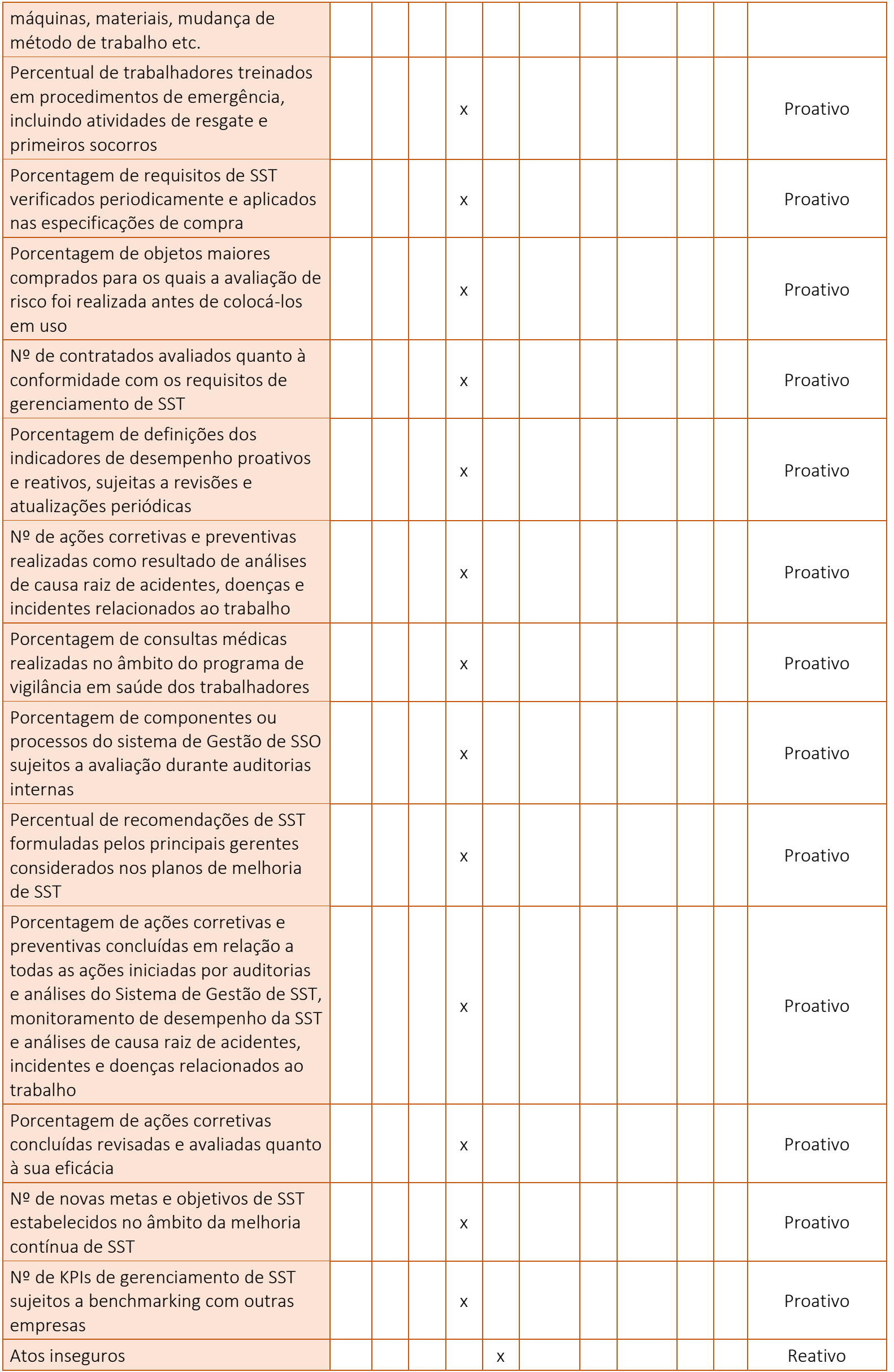




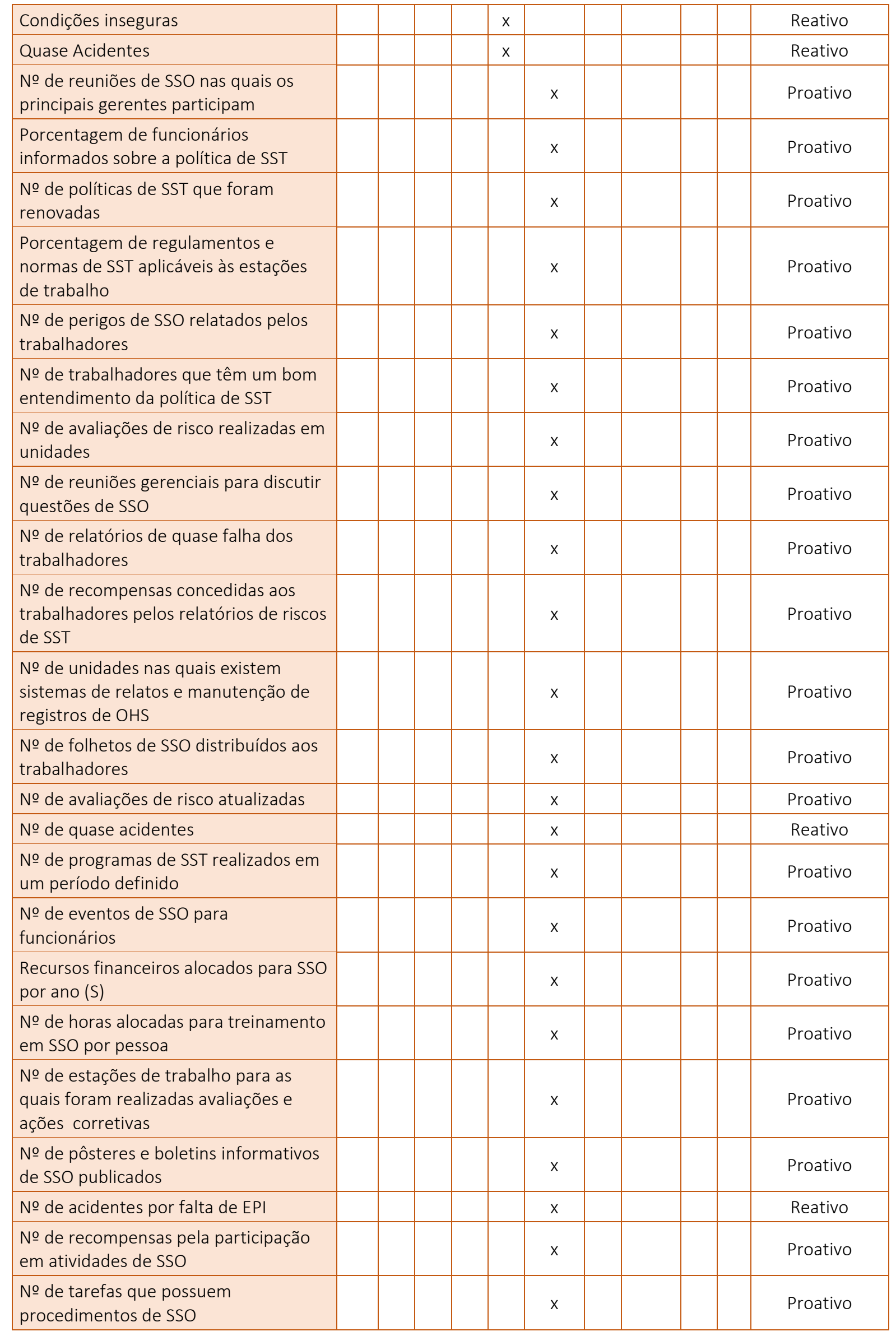




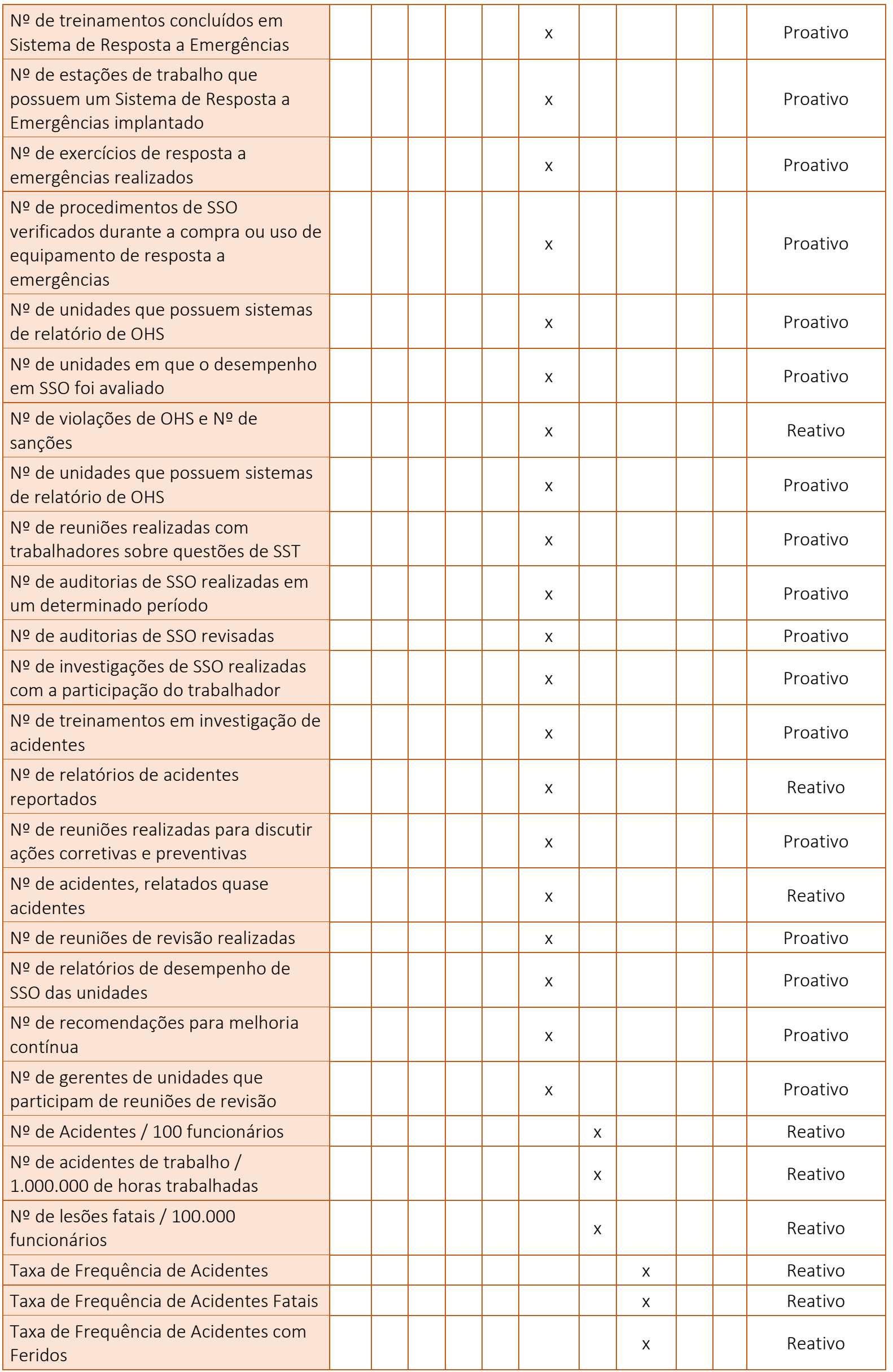




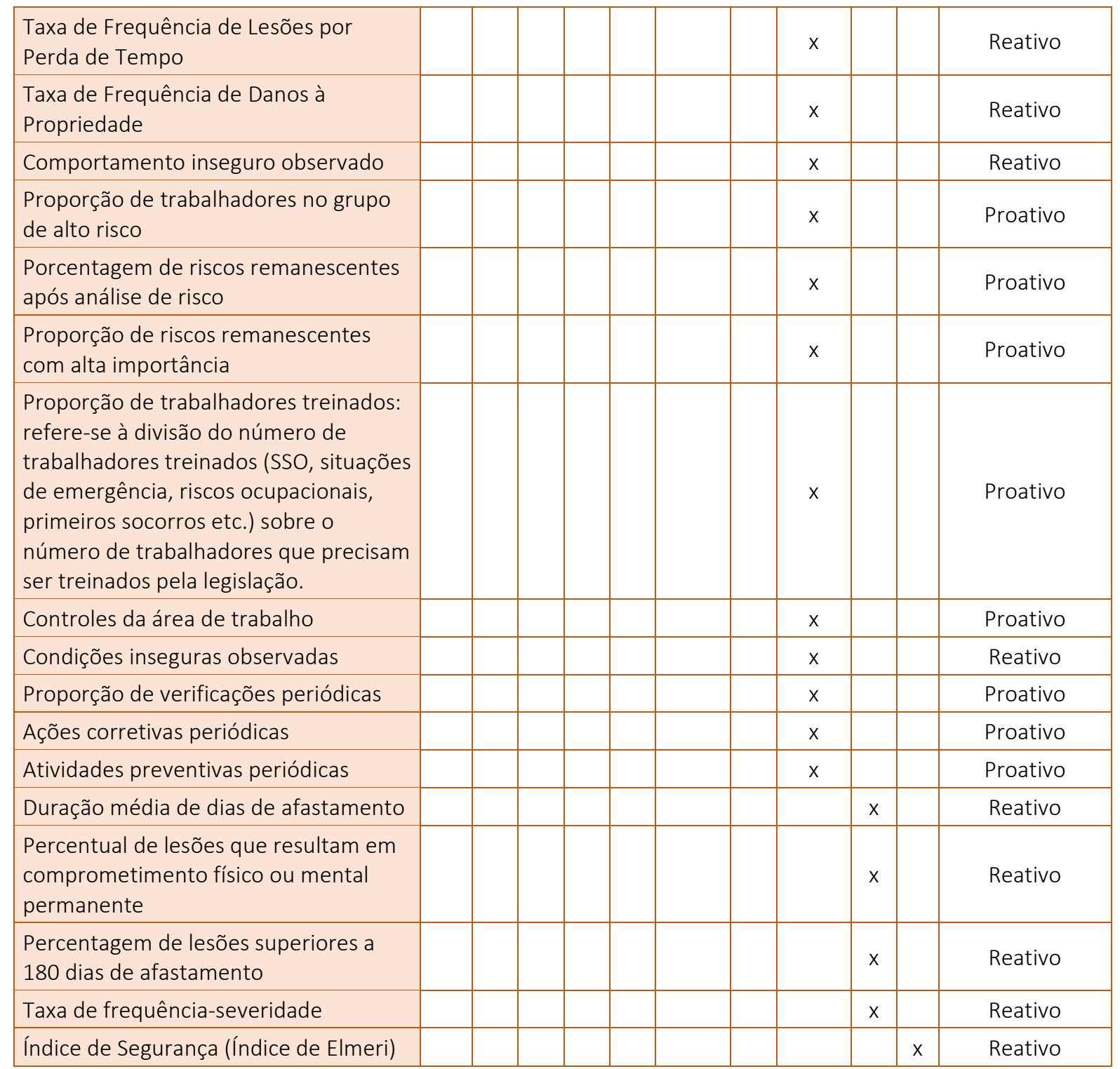

Fonte: Os autores 